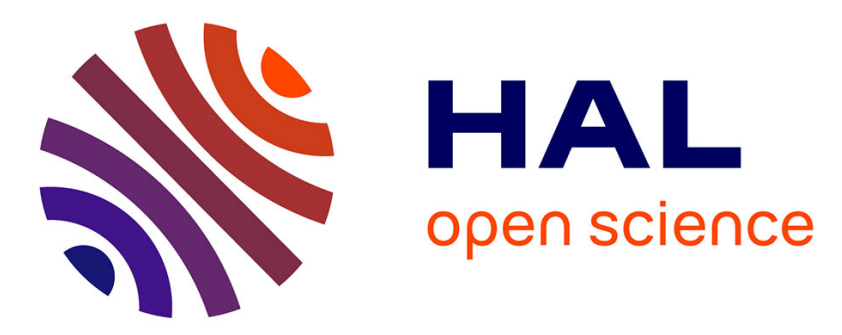

\title{
Catalytic Pyrolysis of Waste Engine Oil over Y Zeolite Synthesized from Natural Clay
}

Gabriel Kofi Osei, Ange Nzihou, Abu Yaya, Doan Pham Minh, B.

Onwona-Agyeman

\section{To cite this version:}

Gabriel Kofi Osei, Ange Nzihou, Abu Yaya, Doan Pham Minh, B. Onwona-Agyeman. Catalytic Pyrolysis of Waste Engine Oil over Y Zeolite Synthesized from Natural Clay. Waste and Biomass Valorization, 2021, 12, pp.4157-4170. 10.1007/s12649-020-01282-0 . hal-02980798

\section{HAL Id: hal-02980798 https://imt-mines-albi.hal.science/hal-02980798}

Submitted on 29 Oct 2020

HAL is a multi-disciplinary open access archive for the deposit and dissemination of scientific research documents, whether they are published or not. The documents may come from teaching and research institutions in France or abroad, or from public or private research centers.
L'archive ouverte pluridisciplinaire HAL, est destinée au dépôt et à la diffusion de documents scientifiques de niveau recherche, publiés ou non, émanant des établissements d'enseignement et de recherche français ou étrangers, des laboratoires publics ou privés. 


\title{
Catalytic Pyrolysis of Waste Engine Oil over Y Zeolite Synthesized from Natural Clay
}

\author{
Gabriel Kofi Osei $^{1,2,3} \cdot$ Ange Nzihou $^{2} \cdot$ Abu Yaya $^{1} \cdot$ Doan Pham Minh $^{2} \cdot$ B. Onwona-Agyeman ${ }^{1}$ (1)
}

\begin{abstract}
Cheap alumino-silicate materials such as clay materials and Y zeolite were selected for the catalytic pyrolysis of waste engine oil in a fixed bed reactor. A cheaper route of Y zeolite synthesis involving hydrothermal activation of the raw clay and hydrothermal synthesis was employed. X-ray diffraction technique, scanning electron microscopy, Fourier transform infra-red, and nitrogen desorption method were used to characterize the intermediate phases formed during the hydrothermal treatment of the clay and the synthesized Y zeolite during the hydrothermal processes. The chemical compositions of the liquid phase of catalytic pyrolysis were characterized by gas chromatography coupled with mass spectroscopy (GC-MS). The results revealed that the alkaline concentration strongly influenced the activation of the raw clay to obtain a useful phase for the subsequent synthesis of the Y zeolite. The synthesis improved the surface area from $29 \mathrm{~m}^{2} / \mathrm{g}$ for the clay to $745 \mathrm{~m}^{2} / \mathrm{g}$ for the zeolite. The catalytic pyrolysis resulted in diesel fractions of 64.8 and $54.7 \%$, respectively for the Y zeolite and the clay. It was observed that the gasoline fractions increased to 20.5 and $19.1 \%$, respectively for the zeolite and the clay. In the diesel fraction, the zeolite selectively improved the yield of the cyclo-alkanes which are key constituents in terms of the quality of diesel. Y zeolite was successfully derived from a natural clay and tested in the pyrolysis of waste engine oil. The synthesis route provides the opportunity to improve the catalytic property of the natural clay.
\end{abstract}

\section{Graphic Abstract}

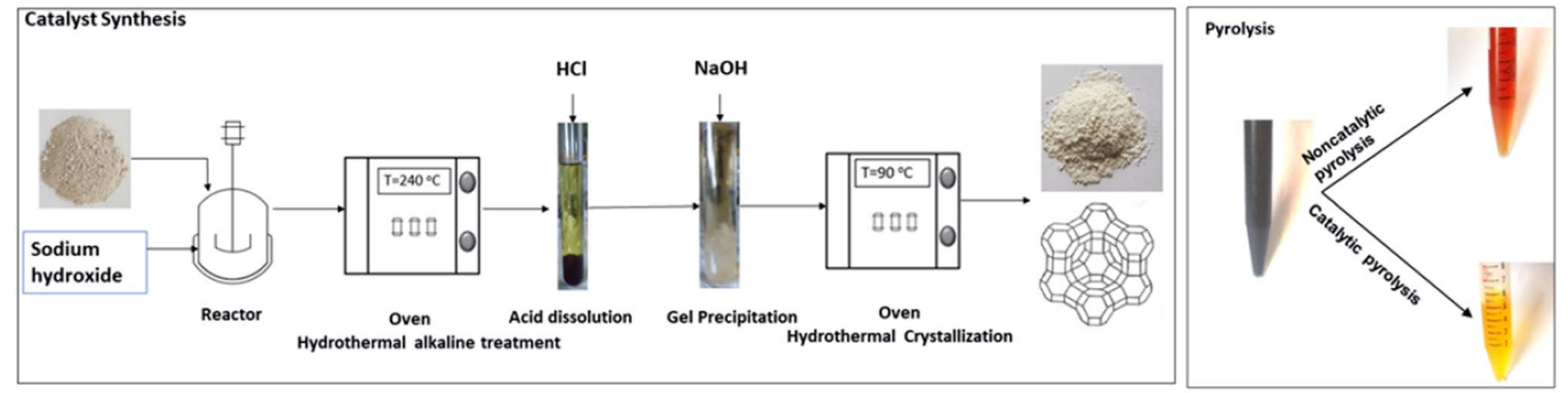

Keywords Waste engine oil · Catalytic pyrolysis $\cdot$ Hydrothermal activation $\cdot$ Y zeolite $\cdot$ Natural clay

B. Onwona-Agyeman

bonwona-agyeman@ug.edu.gh

1 Department of Materials Science and Engineering, School of Engineering Sciences, University of Ghana, Legon, Ghana

2 Université de Toulouse, Mines Albi, CNRS, Centre RAPSODEE, Campus Jarlard, 81013 Albi Cedex 09, France

3 Department of Automotive Engineering, Faculty of Engineering, Koforidua Technical University, Koforidua, Ghana

\section{Statement of Novelty}

Waste engine oil disposal is problematic in developing countries and this is due to the inadequate waste management system. This study investigates the possibility of converting waste engine oil to useful fuels through catalytic pyrolysis. The use of natural clay, which had not been considered in the pyrolysis of waste engine oil before, was explored both as a 
catalyst and as a raw material for the synthesis of Y zeolite. The hydrothermal process adopted for Y zeolite synthesis prevents the use of chemical reagents which are predominant in the synthesis of alumino-silicate gel. Therefore, the study presents a new perspective for natural clay as a catalyst and as a feedstock for preparing Y zeolite for waste engine valorisation into useful hydrocarbons.

\section{Introduction}

In 2015, the global consumption of lubricating oil was estimated at around 35.8 million tons and out of this, about $50 \%$ of lubricating oil was converted to waste engine oil [1]. To deal with the waste lubricating oil potential challenge, it is predominantly incinerated or used in combustion processes [2]. However, this approach hinders other forms of technologies of valorisation [1] and due to the adverse impact on the environment and emission control mechanism on the incinerators is required [3, 4]. In some developing countries, waste engine oil is spilled on the ground or dumped in municipal drains or streams [5]. This practice can be very detrimental to the environment since one litre of waste oil is sufficient to contaminate 1 million litres of drinking water [6]. As a result of the potential threat, it is important to convert this type of waste into useful hydrocarbons in a sustainable manner with minimal or no risk to the environment.

Catalytic pyrolysis is one of the technologies that can be used to recover hydrocarbons from waste engine oil since it has the benefit of selectively producing specific organic compounds. The mechanisms of catalytic pyrolysis reactions including those use to eliminate some undesired compounds can be categorised into decarbonylation, decarboxylation, hydrocracking, hydrodeoxygenation and hydrogenation [7-9]. In recent studies, the catalysts that have been used in pyrolysis of waste engine oil include natural magnetite [10], barium-strontium ferrite [11], and zeolites [12]. Some of these studies focused on the influence of the catalysts on the production of diesel fractions while others focus on eliminating oxygenated compounds during the catalytic pyrolysis.

Zeolites have been extensively used in catalytic pyrolysis and this is because of its ability to selectively catalyse some organic reactions. This ability is derived from the pore structure that gives the catalytic shape-selective behaviour of zeolites. On the contrary, alumino-silicate materials such as clay minerals have received less attention in catalysing organic reactions. The reasons include the typical variability of natural clays, wide variety of clay minerals and, also, the activity and selectivity of clays for cracking organic compounds are lower than that of zeolites $[13,14]$. Nonetheless, these reasons should no longer suffice to relegate clays as catalysts for hydrocarbon cracking since clays have interesting properties such as Bronsted and Lewis acid sites [15]. Recently, few studies have reported the application of clays as catalysts in pyrolysis of polypropylene, peat, lignin, almond shell, and wood chips [16-20].

Apart from clay being considered as catalysts, it can serve as alumino-silicate sources for the synthesis of zeolite and this can reduce or eliminate the use of chemical reagents during zeolite synthesis. Using clay in this manner can be viewed as enhancing the catalytic properties of the natural clay. Studies have shown that it is possible to synthesize zeolites such as fujasites, LTA and mordenites frameworks from clay minerals [21-25]. However, the use of chemicals remains as the source of achieving the $\mathrm{Si} / \mathrm{Al}$ ratio. Also, an appropriate $\mathrm{Si} / \mathrm{Al}$ composition of clay does not guarantee the synthesis of a particular zeolite [26]. Though Wang et al. [23] have shown that one of the key parameters is $\mathrm{Si} / \mathrm{Al}$ ratio and this dependency may be attributed to the method of zeolite synthesis.

The catalytic properties of clays in the pyrolysis of waste engine oil have not been investigated yet and, in spite of the plethora of studies of pyrolysis involving zeolites, few studies have employed $\mathrm{Y}$ zeolite in the pyrolysis of waste engine oil. Therefore, this study focuses on the synthesis of Y zeolite from a natural clay with a controlled Si/Al molar ratio. Additionally, Y zeolite and the natural clay were investigated in the catalytic pyrolysis of a selected waste engine oil in order to explore a new route for the valorization of this abundant waste.

\section{Materials and Methods}

\section{Materials}

The natural clay was collected from Anfoega, a town located in the Volta region of Ghana. The lumps of the clay collected were crushed into fine particle sizes. The crushed samples were dried in an oven at $105{ }^{\circ} \mathrm{C}$ overnight. The dried clay was sieved and particle sizes less than $50 \mu \mathrm{m}$ were retained for the synthesis of Y zeolite. Sodium hydroxide $(\mathrm{NaOH})$ pellet $(\geq 98.9 \%$ ) of analytical grade was purchased from Thermo Fisher Scientific and hydrochloric acid $(\mathrm{HCl}, 37$ wt\%) was purchased from Chem-Lab (Belgium). The waste engine oil was collected from diesel engines in a garage in Albi city (France).

\section{Methods}

\section{Synthesis of $Y$ Zeolite}

Y zeolite was synthesized according to the method used by Wang et al. [23]. Approximately $2 \mathrm{~g}$ of the natural clay was mixed with $16 \mathrm{~mL}$ of $6 \mathrm{M}$ aqueous solution of $\mathrm{NaOH}$. To investigate the impact of the alkaline concentration, 
additional experiments were carried out for 8 and $10 \mathrm{M}$ aqueous solution of $\mathrm{NaOH}$. The mixture was then transferred into a $5 \mathrm{~mL}$ stainless steel high-pressure autoclave and heated in an oven at a temperature of $240{ }^{\circ} \mathrm{C}$ for $2 \mathrm{~h}$. Similar experiments were carried out for 4 and $6 \mathrm{~h}$ to investigate the impact of residence time during the activation process in the autoclave. After the activation process, the autoclave was rapidly cooled down with tap water to discontinue any further reaction. The resulting mixture was then decanted and filtered to obtain the solids while the supernatant was recovered and kept for later use. A sample for analyses was prepared from the filtered solids by rinsing with deionized water and continuously centrifuged, after which it was dried in a desiccator for $12 \mathrm{~h}$. The remaining filtered solid materials were dispersed in water and vigorously mixed to form a homogeneous slurry. To perform acid dissolution of the solids, a $5 \mathrm{ml}$ solution of $37 \% \mathrm{HCl}$ was added to the slurry at room temperature. The remaining solids and impurities in the transparent solution were filtered out and rinsed with deionized water and dried in a desiccator for $12 \mathrm{~h}$ for further analyses. Consequently, $\mathrm{NaOH}$ solution was used to precipitate a white gel from the transparent solution obtained from the acid dissolution. The white gel was filtered out of the solution and transferred into the autoclave for hydrothermal crystallization at $90{ }^{\circ} \mathrm{C}$ for varied residence times of 2,6 and $8 \mathrm{~h}$. The resulting solids from this process were washed with deionized water and dried in an oven for $12 \mathrm{~h}$ at $105^{\circ} \mathrm{C}$.

\section{Catalytic Pyrolysis of Waste Engine Oil}

The catalytic pyrolysis of the waste engine oil was performed in a horizontal fixed-bed quartz reactor that was electrically heated. The reactor was initially purged with nitrogen at the rate of $80 \mathrm{~mL} / \mathrm{min}$ and heated to $500{ }^{\circ} \mathrm{C}$. For the non-catalytic pyrolysis, $2 \mathrm{~g}$ of waste engine oil was added into an inert ceramic crucible and carefully inserted into the centre of the reactor where the temperature was fixed at $500{ }^{\circ} \mathrm{C}$. Pyrolysis occurs between 300 to $600{ }^{\circ} \mathrm{C}$ but typically the boiling point of lubricants is $400{ }^{\circ} \mathrm{C}$ [44]. Thus, this limits the range of pyrolysis temperatures between 400 and $600{ }^{\circ} \mathrm{C}$. Increasing the temperature mostly improves the yields of the pyrolysis gases and since the goal of this study is to recover the liquid fuels, this informed the choice of the temperature. Prior to the catalytic pyrolysis, the catalysts were dried in an oven at $105{ }^{\circ} \mathrm{C}$ to remove any residual moisture. For the catalytic pyrolysis, $2 \mathrm{~g}$ of waste engine oil was mixed with the natural clay or Y zeolite (up to $1 \mathrm{~g}$ ) in an inert ceramic crucible. This latter was quickly inserted into the centre of the reactor. The pyrolysis vapour resulting from the reactor was channelled through two impinger bottles containing isopropanol that were fixed in an oil cooler at a temperature of $-5^{\circ} \mathrm{C}$. The solid residue that represents carbon deposition was measured by the difference in the mass of the crucible together with waste engine oil and catalyst before pyrolysis and the mass of crucible together with catalyst and carbon deposit after pyrolysis. The recovered pyrolysis oil was measured by the difference in the mass of impinger bottles with isopropanol before pyrolysis and the mass of impinger bottles with isopropanol and condensed oil after pyrolysis. The yield of the pyrolysis gases was measured by the difference in the mass of the waste engine oil and the masses of the pyrolysis oil and the carbon deposits.

\section{Characterization}

The crystalline structure of natural clay and $\mathrm{Y}$ zeolite was monitored using a Phillips PANalytical X'pert Pro MPD diffractometer with a $\mathrm{Cu} \mathrm{K} \alpha(1.543 \AA)$ radiation source. In conjunction with the XRD analysis, the morphology of these materials was investigated with the scanning electron microscopy (Philips XL30 ESEM) (SEM). The elemental analysis was carried out with X-ray fluorescence analysis (PANalytical Epsilon 3-XL), while CHNSO analysis was performed by using a Flash 2000 analyzer. Also, Fourier Transform Infrared (FTIR) analysis was carried with a Shimadzu FTIR $8400 \mathrm{~S}$ (resolution of 0.8) spectrometer in the wavenumber range of 4000 to $400 \mathrm{~cm}^{-1}$. The FTIR analysis was carried out in transmission mode and the number of scans was 10 . The textural properties were analyzed with nitrogen adsorption-desorption at $77 \mathrm{~K}$ using a Micromeritics 3Flex apparatus. Before the analysis, samples were degassed at $90^{\circ} \mathrm{C}$ for $1 \mathrm{~h}$ and the temperature was increased to $150{ }^{\circ} \mathrm{C}$ at $5{ }^{\circ} \mathrm{C} / \mathrm{min}$ and maintained at this temperature for $12 \mathrm{~h}$. The specific areas were determined using the BET method while the micropore surface area and micropore volumes were also calculated with $t$-plot and Horvath-Kawazoe (HK) methods, respectively.

The chemical compositions of the waste engine oil and the pyrolysis oil samples were identified offline using a 6890 GC-MS (Shimadzu).

\section{Statistical Analysis}

All the experiments were conducted in triplicates and the results calculated are the averages of the data obtained from the experiment. In addition, standard deviations were also calculated and where necessary in the manuscript, the standard deviations have been displayed.

\section{Results and Discussions}

\section{The Natural Clay Characteristics}

The chemical compositions of the Anfoega clay are reported in Table 1, while Fig. 1 shows the crystalline structure of the 
natural clay. The natural clay was characterised by kaolinite (Kaol), muscovite (M), quartz (Q), and montmorillonite (Mt). The chemical composition of the raw clay shows that the major oxides present were $\mathrm{SiO}_{2}$ and $\mathrm{Al}_{2} \mathrm{O}_{3}$ with respective compositions estimated at 48 and $13 \%$ by mass, while the $\mathrm{Fe}_{2} \mathrm{O}_{3}$ and $\mathrm{K}_{2} \mathrm{O}$ contents were around $2 \%$ by mass, respectively. The $\mathrm{Si} / \mathrm{Al}$ molar ratio of the natural clay was found to be 3.18 and this was sufficient for the Y zeolite synthesis. The high molar ratio of $\mathrm{Si}$ to $\mathrm{Al}$ indicated that there was a high amount of $\mathrm{SiO}_{2}$ in the clay and this was mainly due to the presence of quartz.

\section{Hydrothermal Alkaline Activation of Clay}

Clay is a structured material and this makes the silica and alumina compositions unreactive, therefore, there is a need to activate these compositions. During the activation process, clay is transformed structurally into zeolitic minerals such as hydroxycancrinite and analcime phases. The levels of alkaline concentration play a crucial role in the phases obtained during the activation of clay through the hydrothermal process. Wang et al. [23] have shown that lower alkaline concentrations transform the phases in clays to the analcime phase while higher concentrations lead to the hydroxycancrinite phase. Also, other studies used feldspar [27] and fly ash [28] for the synthesis of hydroxycancrinite and analcime phases and revealed that the formation of these phases is mainly dependent on the levels of alkaline concentration. Understanding the formation of these phases is important since hydroxycancrinite which is acid-soluble is useful in the synthesis of Y zeolite. However, the analcime phase is insoluble in acid medium, therefore, it is not possible to synthesize $\mathrm{Y}$ zeolite from analcime.

In view of this, high levels of concentration of $\mathrm{NaOH}$ were chosen in the hydrothermal alkaline activation of the clay samples. Additionally, the residence time in the hydrothermal activation was also varied to investigate its effect on the activation of the clay samples. Table 2, Figs. 2 and 3 show the yields of phase dissolved in the acid medium,

Table 1 Chemical composition of the natural clay

\begin{tabular}{|c|c|}
\hline Oxides & Composition ( $\%$ by mass) \\
\hline $\mathrm{Al}_{2} \mathrm{O}_{3}$ & $12.82 \pm 0.08$ \\
\hline $\mathrm{SiO}_{2}$ & $48.06 \pm 0.15$ \\
\hline $\mathrm{Fe}_{2} \mathrm{O}_{3}$ & $2.08 \pm 0.00$ \\
\hline $\mathrm{MgO}$ & $0.46 \pm 0.01$ \\
\hline $\mathrm{K}_{2} \mathrm{O}$ & $2.75 \pm 0.04$ \\
\hline $\mathrm{TiO}_{2}$ & $0.85 \pm 0.00$ \\
\hline $\mathrm{P}_{2} \mathrm{O}_{5}$ & $0.064 \pm 0.00$ \\
\hline $\mathrm{V}_{2} \mathrm{O}_{5}$ & $0.021 \pm 0.00$ \\
\hline $\mathrm{Cr}_{2} \mathrm{O}_{3}$ & $0.011 \pm 0.00$ \\
\hline
\end{tabular}

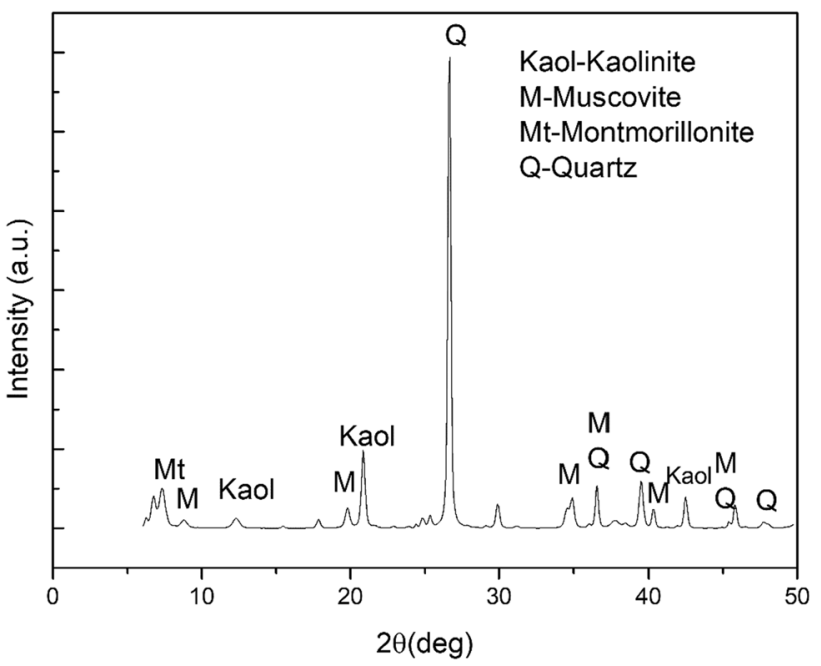

Fig. 1 Phase composition of the Anfoega clay

the XRD patterns and SEM images of phases present after hydrothermal activation, respectively. The XRD patterns of the phases were matched according to collection of simulated XRD patterns for zeolites [29]. It is shown in Fig. 2 that muscovite $(\mathrm{M})$, hydroxycancrinite $(\mathrm{C})$, and analcime (A) phases were detected after $6 \mathrm{M}$ alkaline activation. The muscovite phase obtained in the reaction was as a result of the remnant of the unreacted muscovite phase contained in the raw clay (Fig. 1), however, the hydroxycancrinite and analcime phases were formed as a result of the hydrothermal alkaline activation of the clay samples. The increase in alkaline concentration improved the formation of hydroxycancrinite while the muscovite phase was not detected at higher concentrations during the hydrothermal activation of the clay. This reinforced the results obtained in Table 2 which shows that the yields of acid-soluble phase, hydroxycancrinite, increased from 88.5 to $96 \%$ as the alkaline

Table 2 Alkaline activation of clay and acid dissolution at different times and alkaline concentrations

\begin{tabular}{lll}
\hline $\begin{array}{l}\text { Alkaline } \\
\text { concentra- } \\
\text { tion }(\mathrm{M})\end{array}$ & $\begin{array}{l}\text { Alkaline } \\
\text { Activation } \\
\text { residence time } \\
\text { (h) }\end{array}$ & $\begin{array}{l}\text { Yield of acid-soluble phase resulting } \\
\text { from alkaline activation }(\% \text { by mass) }\end{array}$ \\
\hline 6 & 2 & $88.50 \pm 0.02$ \\
6 & 4 & $91.50 \pm 0.03$ \\
6 & 6 & $94.50 \pm 0.02$ \\
8 & 2 & $93.50 \pm 0.02$ \\
8 & 4 & $95.50 \pm 0.03$ \\
8 & 6 & $96.00 \pm 0.02$ \\
10 & 2 & $96.00 \pm 0.02$ \\
10 & 4 & $96.00 \pm 0.03$ \\
10 & 6 & $96.00 \pm 0.03$ \\
\hline
\end{tabular}




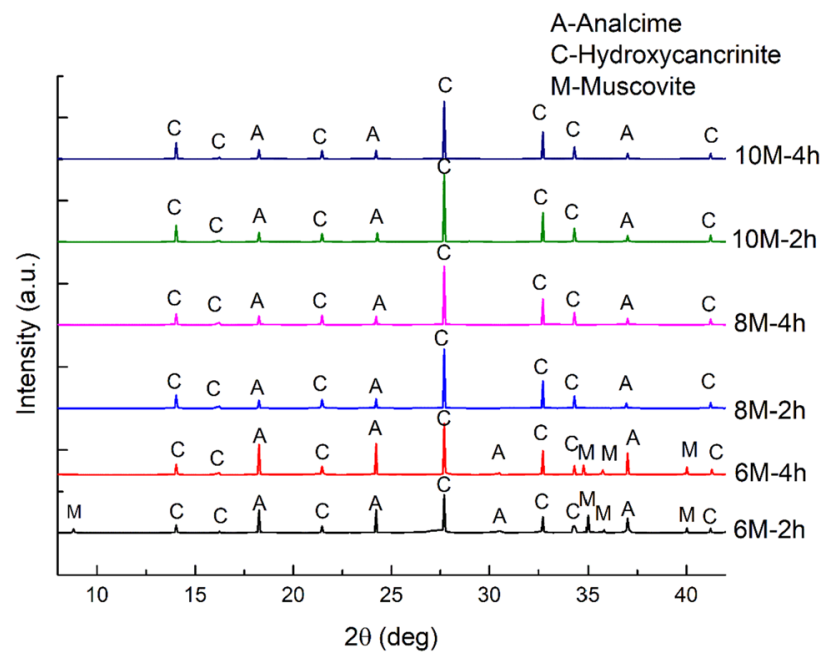

Fig. 2 XRD patterns of phases present after alkaline hydrothermal activation of clay samples

concentration was increased from 6 to $10 \mathrm{M}$. Also, the SEM images revealed the presence of the unreacted muscovite and hydroxycancrinite after the hydrothermal activation of the clay sample with $6 \mathrm{M}$ concentration of $\mathrm{NaOH}$ (Fig. 3a). The muscovite phase exhibits lamellar morphology while the hydroxycancrinite phase exhibits a typical uniform rod morphology. This observation confirmed the effect of increasing alkaline concentration on the production of analcime and hydroxycancrinite phases as studied previously [23, 27, 30].
However, the results revealed that further increase in $\mathrm{NaOH}$ concentration from 8 to $10 \mathrm{M}$ did not remarkably affect the transformation to hydroxycancrinite and this was due to the formation of the analcime phase as displayed in Fig. 3d.

The effect of residence time was also investigated during the activation process and the results are displayed in Table 2 and Fig. 2. As shown in Table 2, increasing the residence times from 2 to $6 \mathrm{~h}$ at $6 \mathrm{M} \mathrm{NaOH}$ hydrothermal activation influenced the yields of acid-soluble phase by increasing the yields from 88.5 to $94.5 \%$. However, increasing the residence times at higher concentrations of 8 and $10 \mathrm{M}$ did not influence the yields of the soluble phase. The increase in the yields at $6 \mathrm{M} \mathrm{NaOH}$ can be explained by the detection of the unreacted muscovite. The muscovite phase was observed at $6 \mathrm{M}$ alkaline concentration, however, the muscovite phase was not observed when the residence times were varied at higher concentrations phase as displayed in Fig. 2.

\section{Y Zeolite Crystallization}

The nucleation and growth of a particular zeolite strongly depend on crystallization temperature and time [26, 31]. Thus, at the beginning of crystallization the starting material which is gel is amorphous and during the crystallization process, some crystals of a desired zeolite may begin to form depending on the temperature and time. However, a sustained increase in crystallization time may cause the dissolution of some zeolites such as zeolite A and zeolite-X into sodalite and zeolite-P, respectively [26]. This phenomenon
Fig. 3 SEM images of hydrothermal alkaline activated clays for $2 \mathrm{~h}$ at varied alkaline concentrations: a $6 \mathrm{M} \mathrm{NaOH}$, b $8 \mathrm{M} \mathrm{NaOH}$, c $10 \mathrm{M} \mathrm{NaOH}$ and d $10 \mathrm{M} \mathrm{NaOH}$
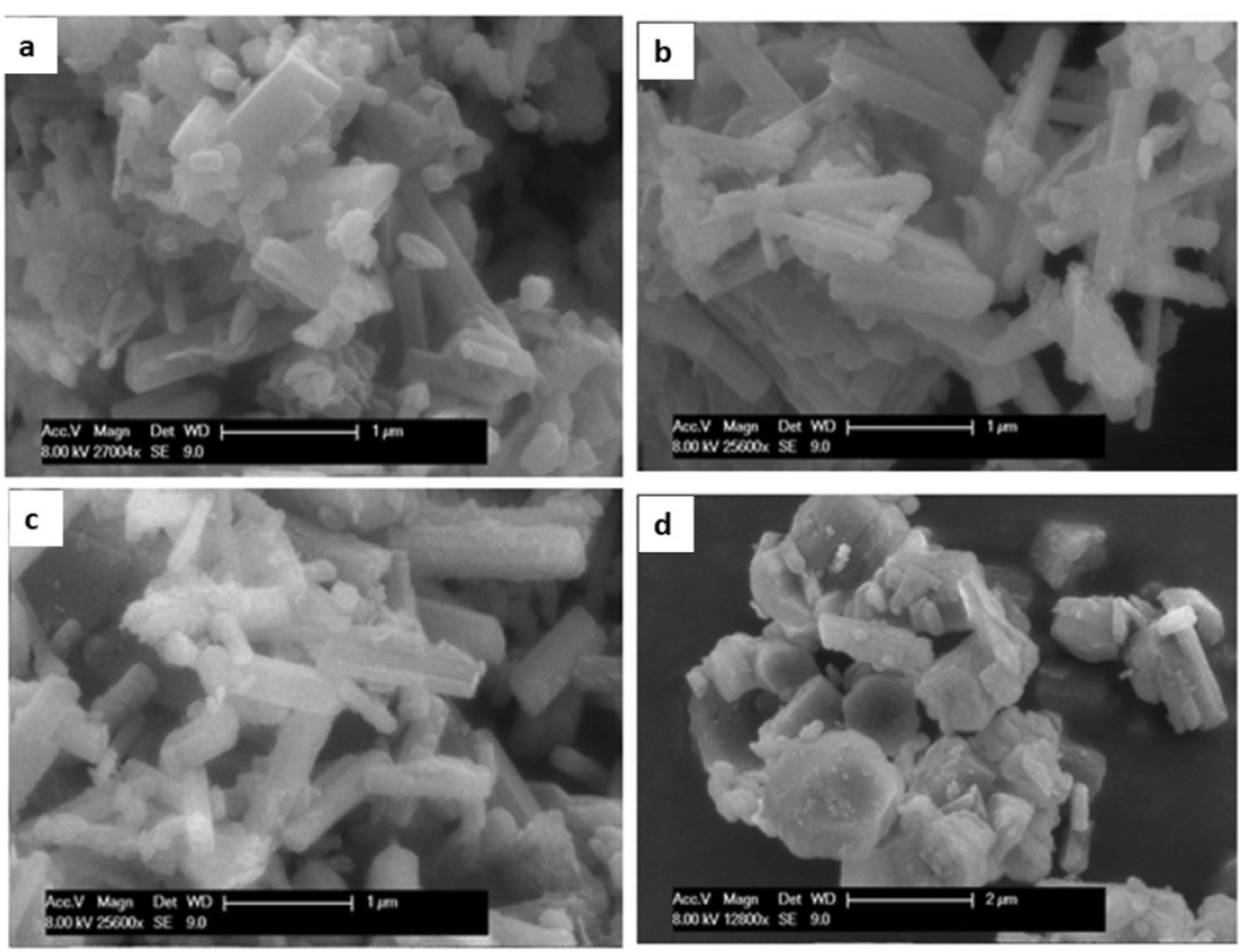
makes the zeolites thermodynamically metastable during crystallization. However, a study has shown that crystallization time significantly affects the quality of the zeolite and not the type of zeolite [32]. Similarly, Wang et al. [23] showed that increasing the crystallization time did not affect the type of zeolite produced.

Figure 4a shows the crystallization of the gel formed from the hydrothermal alkaline activation of the clay. The result demonstrated that at the crystallization time of $2 \mathrm{~h}$, the product remained amorphous with no identifiable reflections. However, as the crystallization time was increased to $4 \mathrm{~h}$, the gel changed from the amorphous state to a crystalline state. Further increase of time to $8 \mathrm{~h}$ caused a distinct appearance of the reflections which indicated crystallization of the zeolite. The intense reflections at $2 \theta=6.3 ; 10.3 ; 12.09$; 15.9; 24.08; and 27.5 match well with Y zeolite according to collection of simulated XRD patterns for zeolites [29]. The results show that at the crystallization time of $2 \mathrm{~h}$ the extracted alumino-silicate material remained amorphous and the nucleation of $\mathrm{Y}$ zeolite was yet to commence and at that moment the nucleation and the growth was not available from the gel. After a sustained increase in the crystallization time to $4 \mathrm{~h}$, the $\mathrm{Y}$ zeolite crystals started to form. The nucleation and growth of the $\mathrm{Y}$ zeolite crystals became pronounced when the crystallization time was increased to $8 \mathrm{~h}$ and it also means that the grains began to multiply. The times for which Y zeolite crystallized in this study are remarkable and compare well in the crystallization times obtained by Wang et al. [23].

Further investigations were carried out to examine the properties of Y zeolite crystallized from different gels obtained from the transformation of the clay sample at varying concentrations of 6,8 and $10 \mathrm{M}$, respectively, at a constant residence time of 2 h. In Fig. 4b, the three FTIR spectra have similar characteristics with no remarkable differences. It could be inferred that increasing the concentration during the hydrothermal treatment did not influence the functional groups of the zeolite produced. Also, all the silica and alumina contents were activated and made available for the formation of Y zeolite. The characteristic FTIR bands of the $\mathrm{Y}$ zeolite framework occur in the band regions of wavenumbers between 1200 to $400 \mathrm{~cm}^{-1}$ [33,34]. For the spectra of the zeolite framework structure, the most prominent bands occur in the ranges of $1250-950 \mathrm{~cm}^{-1}, 790-650 \mathrm{~cm}^{-1}$, and $500-420 \mathrm{~cm}^{-1}$ [35]. Other bands may occur at $650-500 \mathrm{~cm}^{-1}$ and $420-300 \mathrm{~cm}^{-1}$ [35]. The FTIR prominent band of the synthesized zeolites occurred between 1000 and $960 \mathrm{~cm}^{-1}$ while the shoulder appeared between 1100 and $1050 \mathrm{~cm}^{-1}$
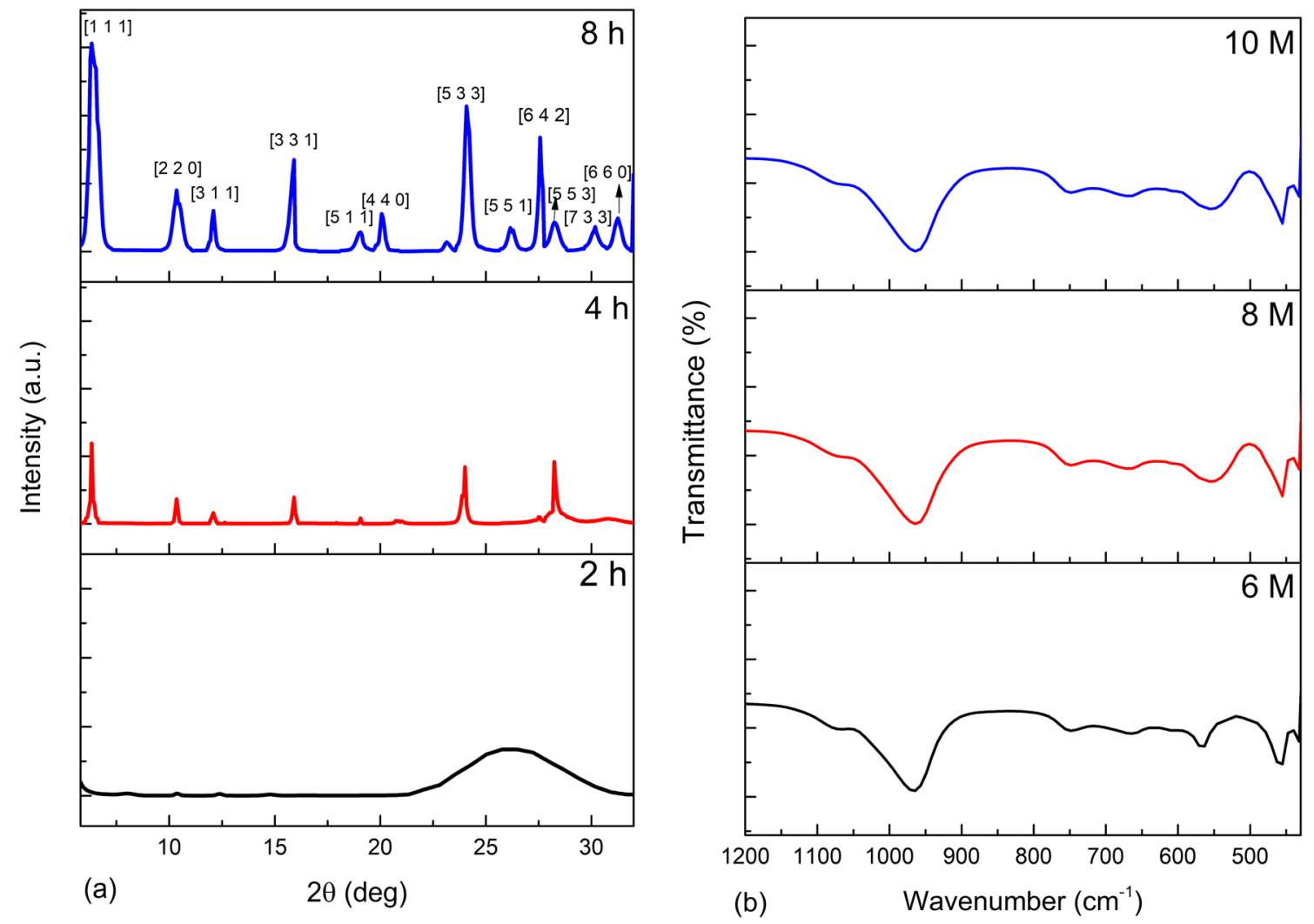

Fig. 4 Hydrothermal crystallization of gel from the hydrothermal activation of the raw clay; a XRD patterns of crystallized zeolite from 6 M $\mathrm{NaOH}$ at different residence times; b FTIR spectra of crystallized Y zeolite at $8 \mathrm{~h}$ for $6 \mathrm{M}, 8 \mathrm{M}$ and $10 \mathrm{M} \mathrm{NaOH}$ 
(Fig. 4b). These bands could be attributed to the asymmetric stretching of the $\mathrm{Si}-\mathrm{O}-\mathrm{Al}$ chain in the zeolite structure. The bands at $750 \mathrm{~cm}^{-1}$ and around $675 \mathrm{~cm}^{-1}$, respectively, were as a result of symmetric stretching modes of $\mathrm{TO}_{4}(\mathrm{~T}=\mathrm{Si}$ or $\mathrm{Al}$ ) while the bands between $600-550 \mathrm{~cm}^{-1}$ and between 500 and $450 \mathrm{~cm}^{-1}$ were ascribed to external linkage vibrations and pore opening vibrations, respectively [34, 35].

Table 3 and Fig. 5 show the textural properties, nitrogen isotherms and pore size distribution of the raw clay and the synthesized Y zeolite. The zeolite exhibited Type 1 reversible adsorption isotherm with a steep rise at low relative pressures (Fig. 5a). This corresponds to microporous material and the filling of narrow micropores [36, 37]. This characteristic of zeolitic material is due to enhanced adsorbent-adsorbate interactions occurring in micropores of molecular dimensions [38]. The physisorption shown by the raw clay was characterized by Type II adsorption isotherm. This corresponds to a non-porous or macroporous adsorbent material which is typical of isotherms exhibited by clays [38]. The synthesis of Y zeolite from the raw clay significantly enhanced the surface area and micropore volume from $29 \mathrm{~m}^{2} / \mathrm{g}$ and $0.0016 \mathrm{~cm}^{3} / \mathrm{g}$ to $745 \mathrm{~m}^{2} / \mathrm{g}$ and $0.251 \mathrm{~cm}^{3} / \mathrm{g}$

Table 3 Textural properties of the raw clay and Y zeolite

\begin{tabular}{lcl}
\hline Textural properties & $\mathrm{S}_{\mathrm{BET}}\left(\mathrm{m}^{2} / \mathrm{g}\right)$ & $\mathrm{V}_{\text {micro }}\left(\mathrm{cm}^{3} / \mathrm{g}\right)$ \\
\hline Raw clay & 29 & $0.001631^{*}$ \\
Y zeolite & 745 & $0.251^{* *}$ \\
\hline
\end{tabular}

*Calculated by t-plot method; **calculated by Horvath-Kawazoe respectively (Table 3). The synthesized Y zeolite exhibited a pronounced surface area when compared to synthesized $\mathrm{Y}$ zeolite in other studies ranging from 346 to $758 \mathrm{~m}^{2} / \mathrm{g}[23$, 34, 36, 37, 39]. Figure 5b shows that the zeolite has two size range micropores-the inner pores of size $0.88 \mathrm{~nm}$ and the outer pores $1.84 \mathrm{~nm}$, both corresponding to micropore volume of $0.251 \mathrm{~cm}^{3} / \mathrm{g}$.

\section{Catalytic Performance of Zeolite and the Raw Clay in the Pyrolysis of Waste Engine Oil}

\section{Effect of Catalysts on Product Yield}

The influence of the synthesized Y zeolite and the raw clay was examined during the pyrolysis of waste engine oil and the resultant effects of the catalysts on the pyrolysis product yield are presented in Fig. 6. The catalyst contents influenced the decrease in both the carbon deposit and the yield of pyrolysis oil recovered when compared to non-catalytic pyrolysis ( $0 \%$ catalyst in Fig. 6). However, a significant increase in the production of pyrolysis gases was observed as the catalyst contents were increased. The significant increase in gas yields $(73 \%)$ of the zeolite can be attributed to the microporous nature of the catalyst (see Fig. 5a) and the high surface area of the zeolite (Table 3). This also confirmed the higher carbon deposits on the zeolite compared with the raw clay which meant that the cracking of waste engine oil was higher on the zeolite. The effect of the high surface area of the zeolites, favouring the gas production during pyrolysis has also been reported by Guimarães et al.
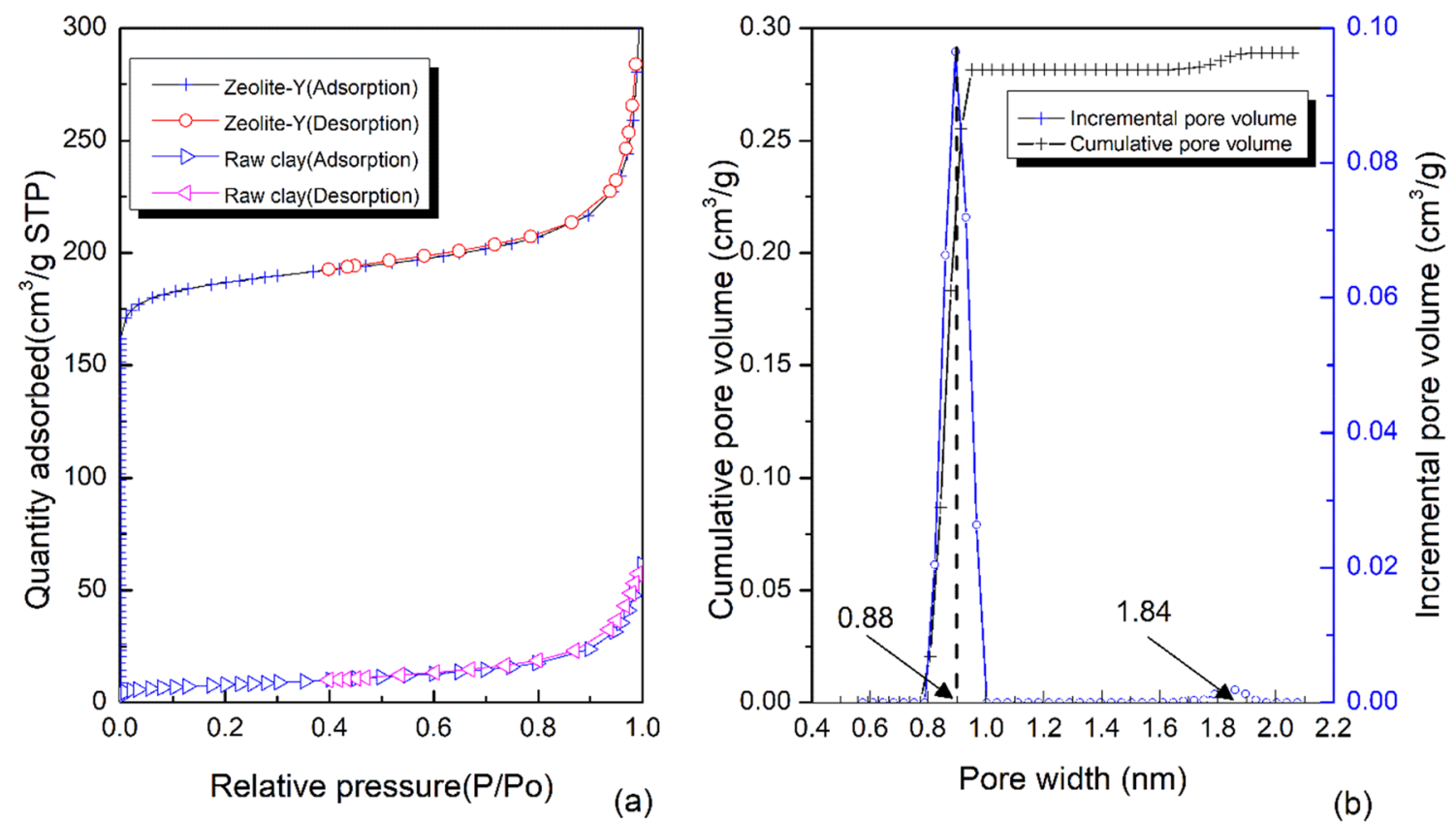

(a)

(b)

Fig. 5 BET analysis of Y zeolite- and raw clay; a Nitrogen sorption isotherms of clay and Y zeolite; $\mathbf{b}$ Pore size distribution curve of Y zeolite 
Fig. 6 Influence of catalyst on pyrolysis product yield; a carbon deposit, b pyrolysis oil yield, $\mathbf{c}$ gas yield

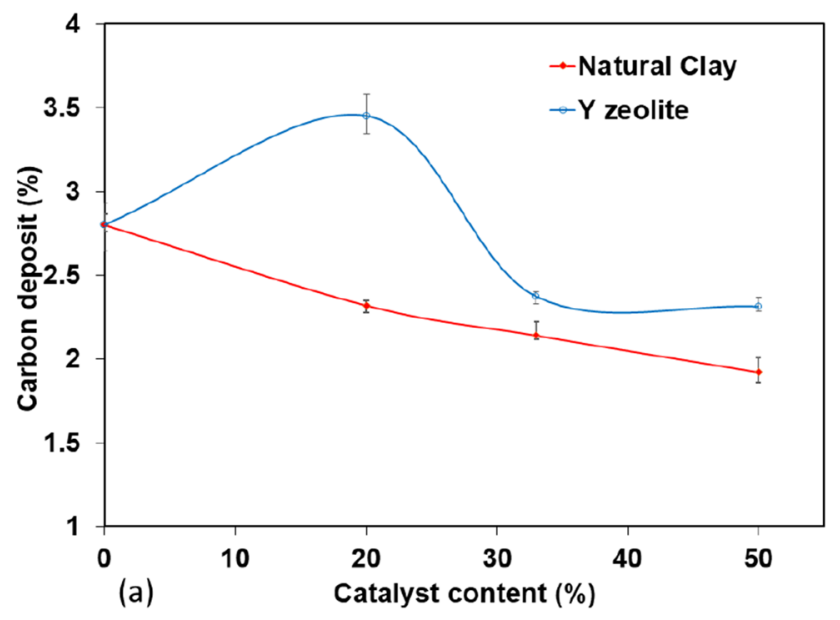

Catalysts Carbon deposit

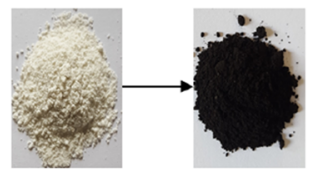

Y zeolite

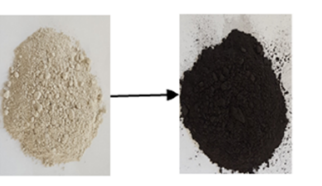

Natural clay

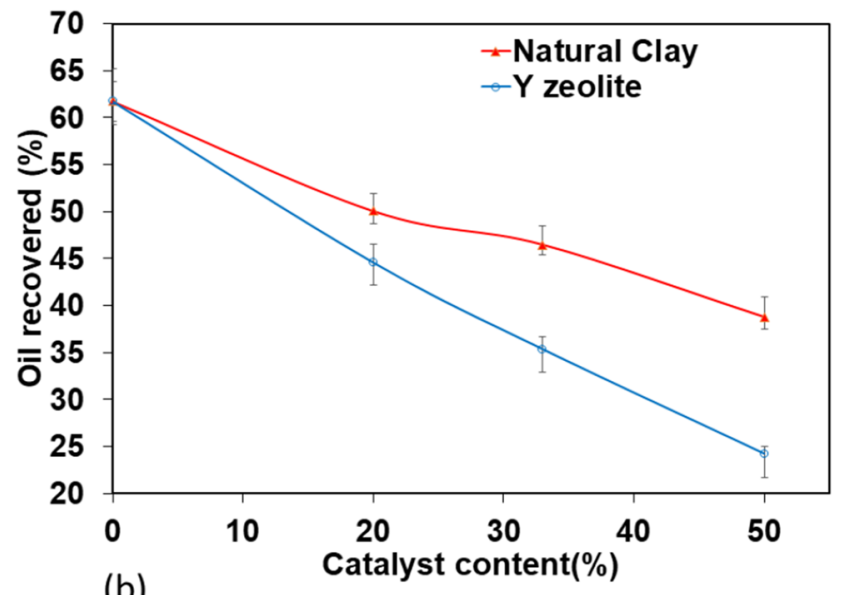

(b)

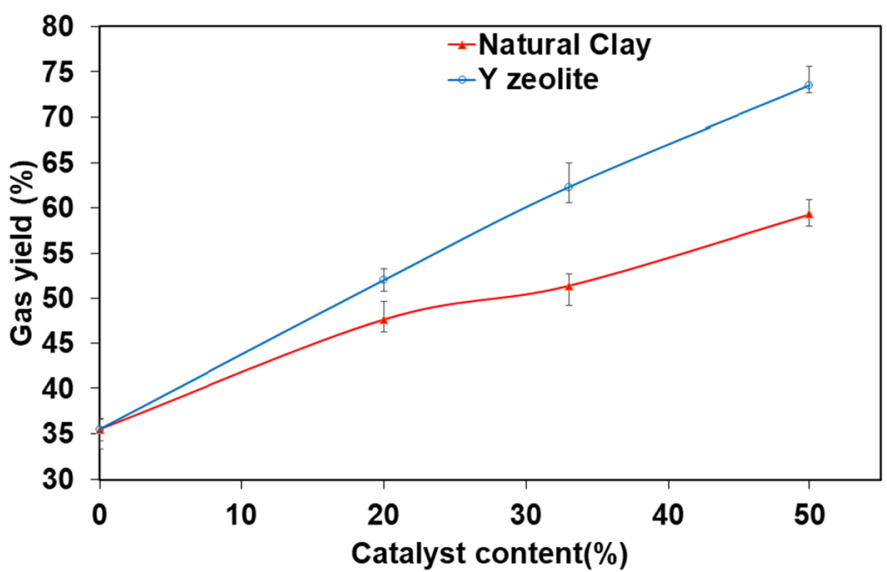

(c)

[40] and Miskolczi et al. [41]. The raw clay favoured the production of pyrolysis oil compared to $\mathrm{Y}$ zeolite as shown in Fig. 6 while carbon deposit for that of the clay was found to be lower than that of the zeolite. This may be attributed to the less acidities of the clay compared to the Y zeolite [42] and the presence of water in the clay [43].

\section{Activity and Selectivity of the Catalysts}

Table 4 and Fig. 7 show the chemical composition of the waste engine oil and it can be observed that the oil was mainly characterised by paraffinic compounds $(84.4 \%)$ while the oxygenated and acidic compounds constituted $11.3 \%$. This is typical of lubricating oils from naphthenic base oil 
Table 4 Chemical characteristics of the waste engine oil

\begin{tabular}{lclc}
\hline Elements & $\begin{array}{l}\text { Composi- } \\
\text { tion (wt\%) }\end{array}$ & Chemical compositions & Peak area (\%) \\
\hline Carbon & 82.7 & Alkanes & 19.46 \\
Hydrogen & 11.61 & Cyclo-alkanes & 64.91 \\
Nitrogen & 0.33 & Aromatics & 0.42 \\
Sulphur & 0.17 & Oxygenates and acids & 11.3 \\
Oxygen $^{\text {a }}$ & 5.19 & & \\
\hline
\end{tabular}

${ }^{\mathrm{a}}$ Calculated by the difference

[44], however, the other compounds found in the waste oil such as hexadecanoic acid methyl ester, methyl 10-trans,12cis-octadecadienoate, 6-Octadecenoic acid methyl ester, and hexanedioic acid, bis(2-ethylhexyl) ester were formed as a result of oxidation reaction during the service life of the lubricant [45].

The focus of this study was to recover liquid fuel through the catalytic pyrolysis of the waste engine oil, therefore, the chemical composition of the oils was investigated and a comparison was drawn between the catalytic pyrolysis and the non-catalytic pyrolysis. This was done to ascertain the effects of the catalysts on the composition of the oxygenated and acidic compounds in the pyrolysis oils. The product distributions of the non-catalytic and catalytic pyrolysis of the waste engine oil as determined from GC-MS analysis are depicted in Fig. 8 and Table 5. It was observed that the main constituents of the non-catalytic pyrolysis of the waste engine include aliphatics, olefins, oxygenated and acidic compounds, and low concentrations of aromatic compounds. The low concentrations of aromatic and oxygenated compounds identified in the non-catalytic pyrolysis oil can be attributed to their low concentrations originally present in the waste engine oil. Interestingly, it was revealed that the formation of olefins was strongly influenced by the uncatalyzed pyrolysis of the waste engine oil. Likewise, an increase in the concentration of the n-alkanes was noticed while there was a drastic decrease in the concentration of cyclo-alkanes from $64.9 \%$ in the waste engine oil to $4.1 \%$ in the uncatalyzed pyrolysis oil. The formation of olefins would be partly as a result of dehydrogenation reaction of the alkanes present in the waste engine oil and this means that unsaturated hydrocarbons were formed from saturated hydrocarbons [12, 46, 47]. Another possible reaction mechanism for the formation of the olefins could be attributed to the protonation of naphthenes (cyclo-alkanes) to form olefins [48]. The uncatalyzed pyrolysis could not promote deoxygenation reaction as the proportion of the oxygenated compound was found to be $12 \%$ (Fig. 8a) and the proportion was almost the same in the waste engine oil.

Similar results of the formation of olefins were found with the zeolite catalytic pyrolysis of the waste engine oil when compared to uncatalyzed pyrolysis. However, the yields of olefins were significantly lower than the uncatalyzed pyrolysis as depicted in Fig. 8b. In the case of the cyclo-alkanes, the yields were higher when compared with uncatalyzed pyrolysis but the zeolitic pyrolysis yielded lower cycloalkanes as compared to the proportion fou Ønd in the waste engine oil. It was found that the zeolite promoted the higher yields of the alkanes from $19.5 \%$ in the waste engine oil to $32 \%$ in the catalysed pyrolysis oil. This revealed that the waste engine oil was selectively cracked to alkanes and olefins by the process of dehydrogenation and hydrogenation of the cyclo-alkanes present in the waste engine oil facilitated by the weak Bronsted acid sites associated with the pores of the $\mathrm{Y}$ zeolite $[12,49]$. It was also observed that the increase in the zeolite proportion during the pyrolysis did not lead to significant commensuration in the yields of the paraffins and the olefins as shown in Fig. 8b. Deoxygenation reaction is very crucial in eliminating oxygenated compounds since
Fig. 7 Example of GC-MS analysis of waste engine oil

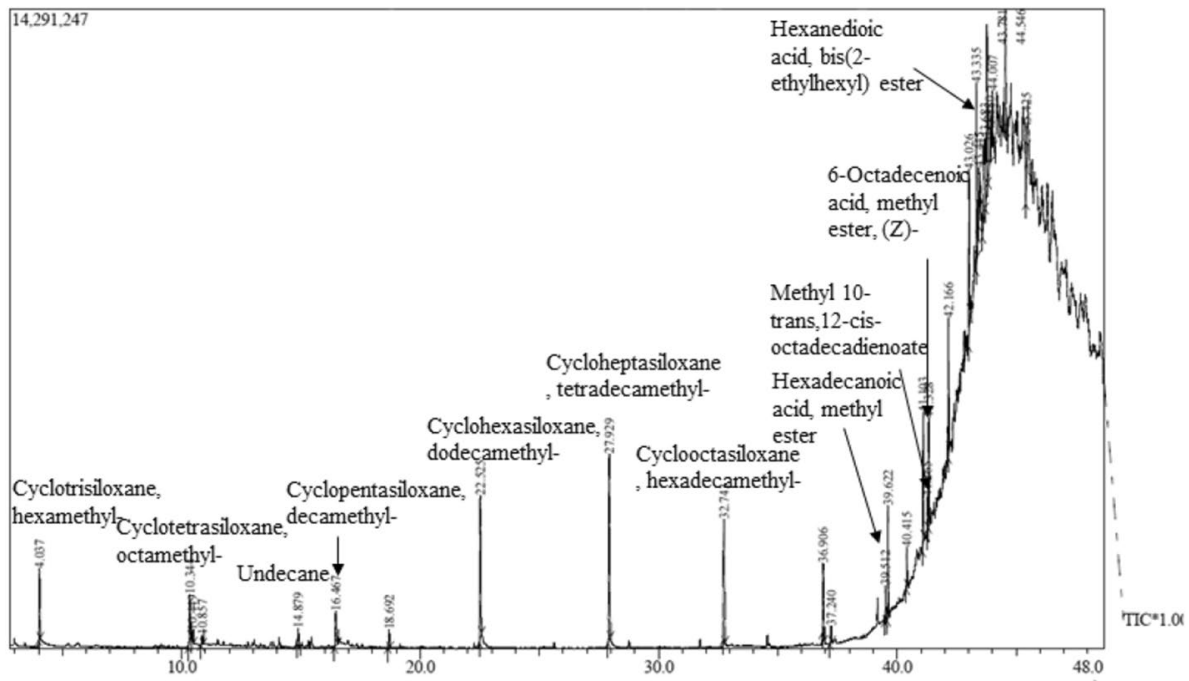


Fig. 8 Catalytic pyrolysis of oil distributions as obtained from the GCMS analysis; a the composition of the paraffins (alkanes and cycloalkanes), the oxygenated and acidic compounds; $\mathbf{b}$ the distribution of the composition of the individual oxygenated and acidic compounds
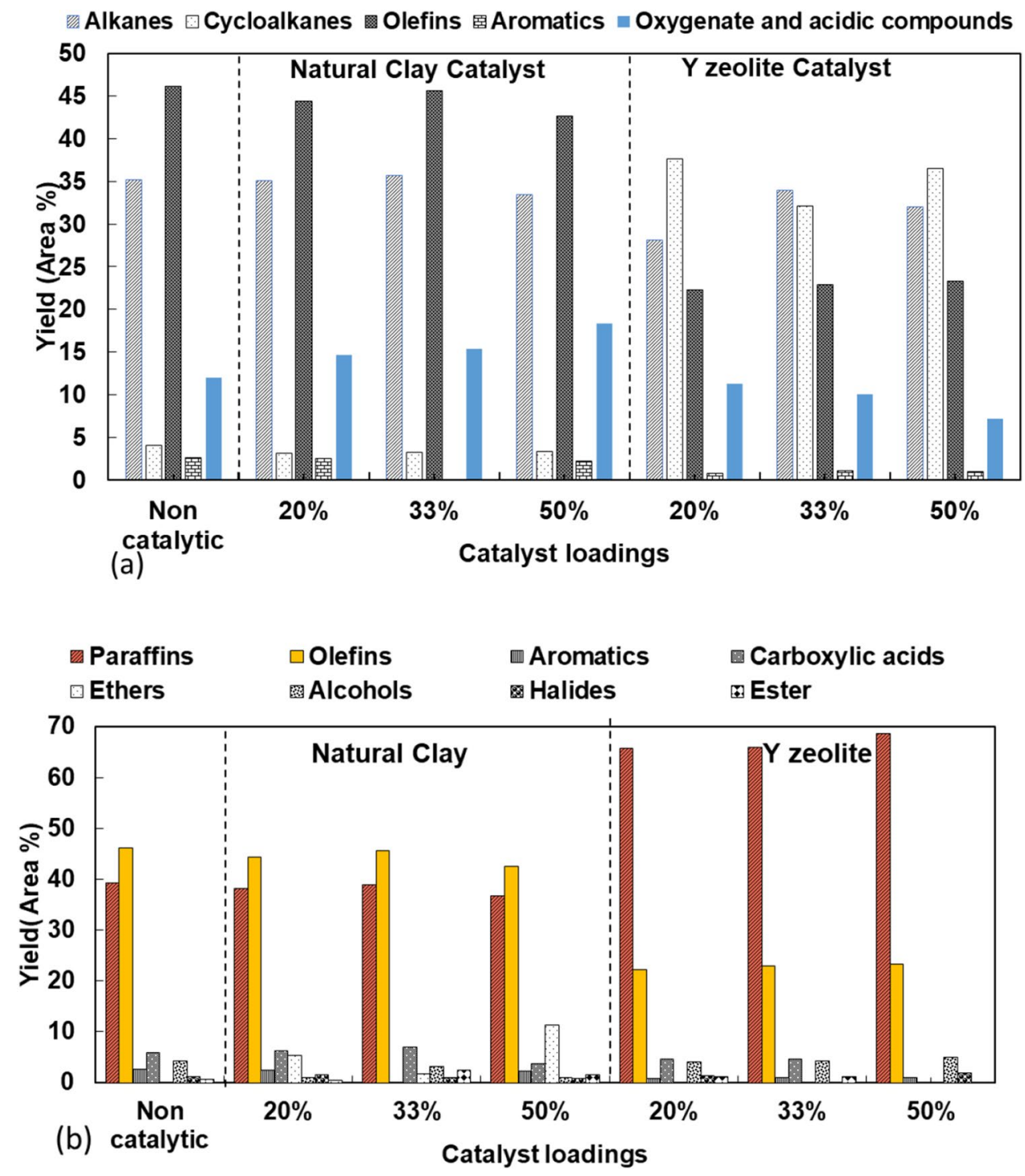

\begin{tabular}{|c|c|c|c|c|}
\hline & Waste Engine Oil & $\begin{array}{l}\text { Uncatalyzed } \\
\text { pyrolysis }\end{array}$ & Clay $(50 \%)$ & Y zeolite $(50 \%)$ \\
\hline Linear/Branched alkanes & 2.09 & 7.58 & 4.23 & 3.49 \\
\hline Linear/Branched olefins & - & - & 14.91 & 6.53 \\
\hline Cyclo-alkanes & 15.28 & - & - & 10.51 \\
\hline Total $\mathrm{C}_{4}-\mathrm{C}_{12}$ composition (Area \%) & 17.37 & 7.58 & 19.14 & 20.53 \\
\hline Linear/Branched alkanes & 2.11 & 26.45 & 23.67 & 22.44 \\
\hline Linear/Branched olefins & & 46.09 & 27.69 & 16.77 \\
\hline Cyclo-alkanes & 43.07 & 4.08 & 3.32 & 25.58 \\
\hline Total $C_{13}-C_{21}$ composition (Area \%) & 45.18 & 76.62 & 54.68 & 64.79 \\
\hline Linear/Branched alkanes & 15.26 & 0.58 & 5.57 & 6.54 \\
\hline Linear/Branched olefins & - & - & - & - \\
\hline Cyclo-alkanes & 6.56 & - & - & - \\
\hline Total of $>C_{21}($ Area $\%)$ & 21.82 & 0.58 & 5.57 & 6.54 \\
\hline
\end{tabular}

The bold values are the summations for each groups
Table 5 Carbon chain length of the product distribution of the pyrolysis oil 
these compounds are responsible for the polymerization of hydrocarbons hence making them unstable and acidic during storage $[7,50]$. It was found that the addition of the Y zeolite promoted deoxygenation reactions and this was evident by the reduction of the oxygenated compounds from 12 to $7.2 \%$ in Fig. 8a. This was due to the selective deoxygenation of the ethers, esters and decarboxylation reaction that culminated in the decrease in ethers, esters and carboxylic acids, respectively.

In the case of the clay catalyst, the yields of cycloalkanes, linear alkanes and olefins appeared to be unaffected when compared with uncatalyzed pyrolysis as shown in Fig. 8a. On the contrary, there was an increase in the oxygenated compounds as the clay catalyst was increased. Kar [19] revealed that some oxygenated compounds increased during the catalytic pyrolysis of almond shell which suggests that clay may not be effective in deoxygenation reaction. In spite of the increase of the oxygenated compounds, a closer look at Fig. 8b showed that the clay catalyst promoted decarboxylation. This was evident as the clay catalyst was increased from 20 to $50 \%$. Zafar and Watson [51] have shown decarboxylation reaction in clay mineral and carboxylic model compounds interaction which showed that the presence of cations in the clay mineral were responsible for the adsorption of carboxylic compounds during the pyrolysis reaction.

The influence of the catalysts on the carbon length was investigated to obtain gasoline and diesel fuel fractions in the pyrolysis reaction. Gasoline and diesel fuels contain mixtures of $\mathrm{C}_{4}-\mathrm{C}_{12}$ and $\mathrm{C}_{13}-\mathrm{C}_{21}$, respectively, while lubricants contain a mixture greater than $\mathrm{C}_{21}[19,52,53]$. On this basis, the pyrolysis oils were categorised as such and the results are illustrated in Table 5. Thermal and catalytic cracking of the heavy hydrocarbons resulted in a significant decrease in the lubricant composition $\left(>\mathrm{C}_{21}\right)$ from $21 \%$ to $0.6,5.6$ and $6.5 \%$, respectively for the uncatalyzed pyrolysis, clay and the zeolite catalysts. The uncatalyzed pyrolysis favoured the production of $\mathrm{C}_{13}-\mathrm{C}_{21}$ that predominantly contained linear/branched olefins $(46.1 \%)$, however, the uncatalyzed pyrolysis yielded about $7.6 \% \mathrm{C}_{4}-\mathrm{C}_{12}$. The low yield of gasoline fraction is typical of non-catalytic pyrolysis of waste engine oil $[46,47]$. This showed that the heavy hydrocarbons in the waste engine oil were predominantly cracked into diesel fraction. In the same way, the main compositions of the two catalysed pyrolysis oils were $\mathrm{C}_{13}-\mathrm{C}_{21}$, nonetheless, it was found that the zeolite and clay catalysts significantly enhanced the production of $\mathrm{C}_{4}-\mathrm{C}_{12}$ to 20.5 and $19.1 \%$, respectively. As part of the $\mathrm{C}_{4}-\mathrm{C}_{12}$ and $\mathrm{C}_{13}-\mathrm{C}_{21}$ compositions, the selectivity of the $\mathrm{Y}$ zeolite towards cyclo-alkanes was higher compared to the clay catalyst and this could be as a result of the differences in the micropore volume as shown in Table 3. Cycloalkanes are valuable constituents of diesel fuel since they are prone to ignition [10] and this meant that the $\mathrm{Y}$ zeolite selectively produced suitable $\mathrm{C}_{13}-\mathrm{C}_{21}$ as diesel fraction.

\section{Conclusions}

Y zeolites were successfully synthesised from natural clay by thermal treatment in an alkaline medium under hydrothermal conditions. This synthesis route allowed converting up to $96 \%$ of the natural clay into Y zeolites. The specific surface area of Y zeolite could reach up to $745 \mathrm{~m}^{2} / \mathrm{g}$. The synthesis route used has significant impact on the energy input compared to metakaolination and fusion methods that are very energy intensive. Also, the use of natural clay in the synthesis provides an avenue to reduce chemical reagents that are predominantly used for the synthesis of zeolites at the industrial scale.

The catalytic performance of the natural clay and Y zeolites were then investigated in the catalytic pyrolysis of a waste engine oil in a fixed bed reactor in order to recover useful hydrocarbons. Y zeolite favoured the production of the gaseous hydrocarbons while the natural clay enhanced the production of the liquid phase. It was found that the carbon deposit was higher on the Y zeolite than on the raw clay.

Deoxygenation reactions were observed to be promoted by the Y zeolite and this led to the reduction of the oxygenated and acidic compounds such as carboxylic acids, esters, and ethers from 12 to $7 \%$. The raw clay largely increased oxygenated compounds even though there was selective interaction with carboxylic acids that culminated in decarboxylation reaction.

The yield of the diesel fractions in the catalytic pyrolysis oil using the zeolite and the clay were found to be 65 and $55 \%$, respectively, however, the yields were observed to be lower than the uncatalyzed pyrolysis (77\%). The zeolite and clay catalysts enhanced the yields of the gasoline fractions to 21 and $19 \%$, respectively. Some factors for the suitability of diesel fuels depend on chemical compositions and one such factor is ignition delay. Results revealed that the diesel fraction from the Y zeolite catalyst contained cyclo-alkanes which are known to be prone to ignition, thereby, making the diesel fraction more suitable than that obtained with natural clay and the uncatalyzed pyrolysis. This opens a new perspective for the valorisation of waste engine oil into useful hydrocarbons by catalytic pyrolysis process.

Acknowledgements This work was supported by University of GhanaCarnegie Corporation of New York through the auspices of 'Building a New Generation of Academics' (BANGA-AFRICA) project. The authors acknowledge Elsa Weiss-Hortala and Nathalie Lyczko for allowing this work to be carried out in their laboratories. Also, the authors acknowledge the efforts of Mickael Ribeiro, Christine Rolland and Sylvie Del-Confetto, all of IMT Mines Albi. 


\section{Appendix A}

See Fig. 9.

Fig. 9 Pyrolysis experimental set-up

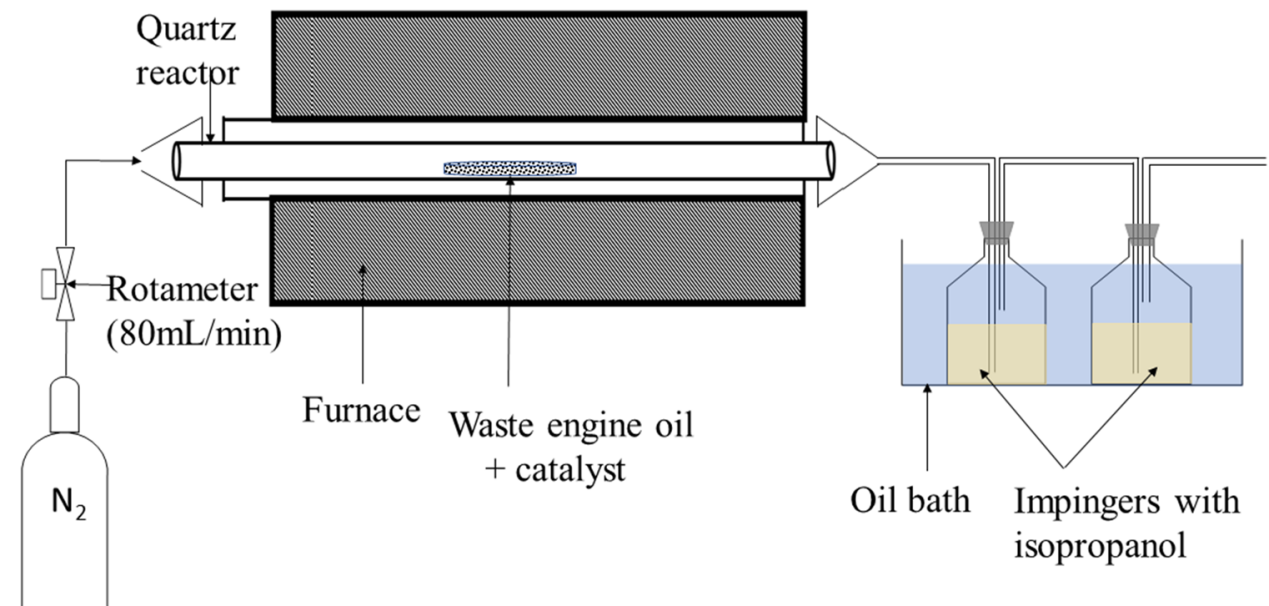

\section{Appendix B}

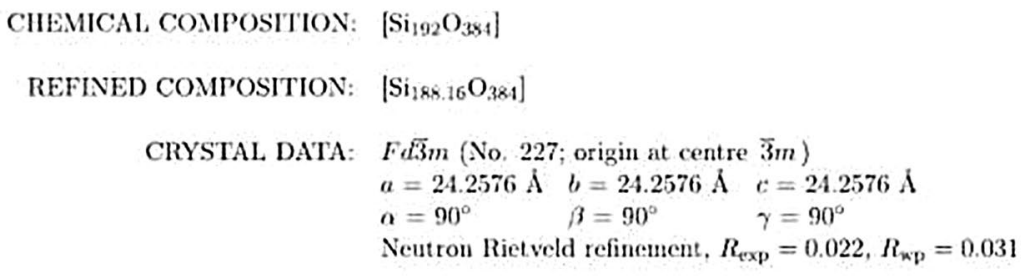

REFERENCE: J. J. Hriljac, M. M. Eddy. A. K. Cheetham, J. A. Donohue and G. J. Ray, J. Solid State Chem. 106 66-72 (1993).
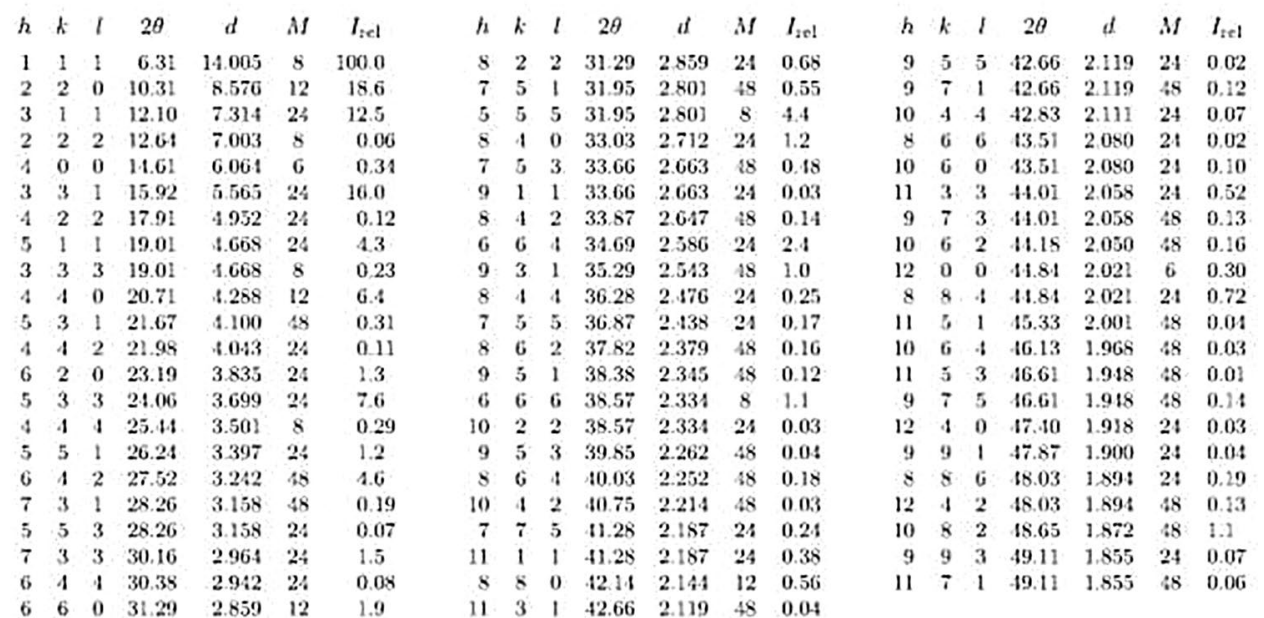


\section{Appendix C}

See Fig. 10.

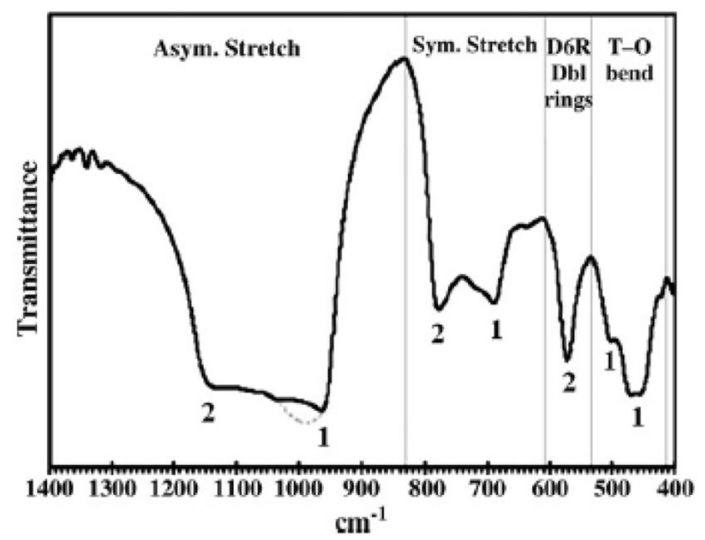

Fig. 10 FTIR Spectra of Y zeolite Adopted from [33-35]

\section{References}

1. Pinheiro, C.T., Ascensão, V.R., Cardoso, C.M., Quina, M.J., Gando-Ferreira, L.M.: An overview of waste lubricant oil management system: physicochemical characterization contribution for its improvement. J. Clean. Prod. 150, 301-308 (2017). https:// doi.org/10.1016/j.jclepro.2017.03.024

2. Kupareva, A., Mäki-Arvela, P., Murzin, D.Y.: Technology for rerefining used lube oils applied in Europe: a review. J. Chem. Technol. Biotechnol. 88, 1780-1793 (2013). https://doi.org/10.1002/ jctb.4137

3. Tabasová, A., Kropáč, J., Kermes, V., Nemet, A., Stehlík, P.: Waste-to-energy technologies: impact on environment. Energy 44, 146-155 (2012). https://doi.org/10.1016/j.energy.2012.01.014

4. Singhabhandhu, A., Tezuka, T.: The waste-to-energy framework for integrated multi-waste utilization: waste cooking oil, waste lubricating oil, and waste plastics. Energy 35, 2544-2551 (2010). https://doi.org/10.1016/j.energy.2010.03.001

5. Mensah-Brown, H.: Re-refining and recycling of used lubricating oil: an option for foreign exchange and natural resource conservation in Ghana. ARPN J. Eng. Appl. Sci. 10, 797-801 (2015). https ://doi.org/10.1002/gsj.1182

6. Submilch, S.: One's Waste, Another's Treasure. Hydrocarbon Engineering, March, 141-143 (2019)

7. Mortensen, P.M., Grunwaldt, J.D., Jensen, P.A., Knudsen, K.G., Jensen, A.D.: A review of catalytic upgrading of bio-oil to engine fuels. Appl. Catal. A Gen. 407, 1-19 (2011). https://doi. org/10.1016/j.apcata.2011.08.046

8. Dickerson, T., Soria, J.: Catalytic fast pyrolysis: a review. Energies. 6, 514-538 (2013). https://doi.org/10.3390/en6010514

9. Nzihou, A., Stanmore, B., Lyczko, N., Minh, D.P.: The catalytic effect of inherent and adsorbed metals on the fast/flash pyrolysis of biomass: a review. Energy. 170, 326-337 (2019). https://doi. org/10.1016/J.ENERGY.2018.12.174

10. Khan, R., Ahmad, I., Khan, H., Ismail, M., Gul, K.: Production of diesel-like fuel from spent engine oil by catalytic pyrolysis over natural magnetite. J. Anal. Appl. Pyrolysis. 120, 493-500 (2016). https://doi.org/10.1016/j.jaap.2016.06.022
11. Ahmad, I., Khan, R., Ishaq, M., Khan, H., Ismail, M., Gul, K., Ahmad, W.: Valorization of spent lubricant engine oil via catalytic pyrolysis: Influence of barium-strontium ferrite on product distribution and composition. J. Anal. Appl. Pyrolysis. (2016). https:// doi.org/10.1016/j.jaap.2016.10.008

12. Tripathi, K.A., Ojha, D.K., Vinu, R.: Selective production of valuable hydrocarbons from waste motorbike engine oils via catalytic fast pyrolysis using zeolites. J. Anal. Appl. Pyrolysis. 114, 281292 (2015). https://doi.org/10.1016/j.jaap.2015.06.009

13. Lagaly, G., Ogawa, M., Dekany, I.: Clay mineral organic interactions. In: Bergaya, F., Lagaly, G. (eds.) Handbook of Clay Science, pp. 309-377. Elsevier Science, Amsterdam (2006)

14. Bergaya, F., Aouad, A., Mandalia, T.: Pillared clays and clay minerals. In: Bergaya, F., Lagaly, G. (eds.) Handbook of Clay Science, pp. 393-421. Elsevier Science, Amsterdam (2006)

15. Theng, B.K.G.: Clay Mineral Catalysis of Organic Reactions. CRC Press Taylor \& Francis Group, LLC, Boca Raton (2018)

16. Hakeem, I.G., Aberuagba, F., Musa, U.: Catalytic pyrolysis of waste polypropylene using Ahoko kaolin from Nigeria. Appl. Petrochemical Res. 8, 203-210 (2018). https://doi.org/10.1007/ s13203-018-0207-8

17. Sulman, M., Kosivtsov, Y., Sulman, E., Alfyorov, V., Lugovoy, Y., Molchanov, V., Tyamina, I., Misnikov, O., Afanasjev, A., Kumar, N., Murzin, D.: Influence of aluminosilicate materials on the peat low-temperature pyrolysis and gas formation. Chem. Eng. J. 154, 355-360 (2009). https://doi.org/10.1016/j.cej.2009.04.001

18. Elfadly, A.M., Zeid, I.F., Yehia, F.Z., Abouelela, M.M., Rabie, A.M.: Production of aromatic hydrocarbons from catalytic pyrolysis of lignin over acid-activated bentonite clay. Fuel Process. Technol. 163, 1-7 (2017). https://doi.org/10.1016/j.fuproc.2017.03.033

19. Kar, Y.: Catalytic cracking of pyrolytic oil by using bentonite clay for green liquid hydrocarbon fuels production. Biomass Bioenerg. 119, 473-479 (2018). https://doi.org/10.1016/j.biomb ioe.2018.10.014

20. Veses, A., Aznar, M., López, J.M., Callén, M.S., Murillo, R., García, T.: Production of upgraded bio-oils by biomass catalytic pyrolysis in an auger reactor using low cost materials. Fuel 141, 17-22 (2015). https://doi.org/10.1016/j.fuel.2014.10.044

21. Belviso, C., Cavalcante, F., Lettino, A., Fiore, S.: A and X-type zeolites synthesised from kaolinite at low temperature. Appl. Clay Sci. 80-81, 162-168 (2013). https://doi.org/10.1016/j. clay.2013.02.003

22. Musyoka, N.M., Missengue, R., Kusisakana, M., Petrik, L.F.: Conversion of South African clays into high quality zeolites. Appl. Clay Sci. 97, 182-186 (2014). https://doi.org/10.1016/j. clay.2014.05.026

23. Wang, J.Q., Huang, Y.X., Pan, Y., Mi, J.X.: New hydrothermal route for the synthesis of high purity nanoparticles of zeolite $y$ from kaolin and quartz. Microporous Mesoporous Mater. 232, 77-85 (2016). https://doi.org/10.1016/j.micromeso.2016.06.010

24. Ayele, L., Pérez-pariente, J., Chebude, Y., Díaz, I.: Conventional versus alkali fusion synthesis of zeolite A from low grade kaolin. Appl. Clay Sci. (2016). https://doi.org/10.1016/j.clay.2016.07.019

25. Mohiuddin, E., Isa, Y.M., Mdleleni, M.M., Sincadu, N., Key, D., Tshabalala, T.: Synthesis of ZSM-5 from impure and beneficiated Grahamstown kaolin: effect of kaolinite content, crystallisation temperatures and time. Appl. Clay Sci. 119, 213-221 (2016). https ://doi.org/10.1016/j.clay.2015.10.008

26. Johnson, E.B.G., Arshad, S.E.: Hydrothermally synthesized zeolites based on kaolinite: a review. Appl. Clay Sci. 97-98, 215-221 (2014). https://doi.org/10.1016/j.clay.2014.06.005

27. Yuan, J., Yang, J., Ma, H., Liu, C., Zhao, C.: Hydrothermal synthesis of analcime and hydroxycancrinite from $\mathrm{K}$-feldspar in $\mathrm{Na}_{2} \mathrm{SiO}_{3}$ solution: characterization and reaction mechanism. RSC Adv. 6, 54503-54509 (2016). https://doi.org/10.1039/c6ra08080d 
28. Oh, J.E., Monteiro, P.J.M., Jun, S.S., Choi, S., Clark, S.M.: The evolution of strength and crystalline phases for alkali-activated ground blast furnace slag and fly ash-based geopolymers. Cem. Concr. Res. 40, 189-196 (2010). https://doi.org/10.1016/j.cemco nres.2009.10.010

29. Treacy, M.M.J., Higgins, J.B.: Collection of Simulated XRD Powder Patterns for Zeolites. Elsevier, Amsterdam (2001)

30. Ma, X., Yang, J., Ma, H., Liu, C., Zhang, P.: Synthesis and characterization of analcime using quartz syenite powder by alkalihydrothermal treatment. Microporous Mesoporous Mater. 201, 134-140 (2015). https://doi.org/10.1016/j.micromeso.2014.09.019

31. Abdullahi, T., Harun, Z., Othman, M.H.: A review on sustainable synthesis of zeolite from kaolinite resources via hydrothermal process. Adv. Powder Technol. 28, 1827-1840 (2017). https://doi. org/10.1016/j.apt.2017.04.028

32. Caballero, I., Colina, F.G., Costa, J.: Synthesis of X-type zeolite from dealuminated kaolin by reaction with sulfuric acid at high temperature. Ind. Eng. Chem. Res. 46, 1029-1038 (2007)

33. Niwa, M., Katada, N., Okumura, K.: Characterization and Design of Zeolite Catalysts Solid Acidity, Shape Selectivity and Loading Properties. Springer, Berlin (2010)

34. Charkhi, A., Kazemeini, M., Ahmadi, S.J., Kazemian, H.: Fabrication of granulated $\mathrm{NaY}$ zeolite nanoparticles using a new method and study the adsorption properties. Powder Technol. 231, 1-6 (2012). https://doi.org/10.1016/j.powtec.2012.06.041

35. Karge, H., Hunger, M., Beyer, H.: Characterization of zeolitesinfrared and nuclear magnetic resonance spectroscopy and X-ray diffraction. In: Weitkamp, J., Puppe, L. (eds.) Catalysis and Zeolites Fundamentals and Applications, pp. 198-326. Springer, Berlin (1999)

36. Otieno, S.O., Kengara, F.O., Kemmegne-Mbouguen, J.C., Langmi, H.W., Kowenje, C.B.O., Mokaya, R.: The effects of metakaolinization and fused-metakaolinization on zeolites synthesized from quartz rich natural clays. Microporous Mesoporous Mater. 290, 109668 (2019). https://doi.org/10.1016/j.micromeso.2019.10966 8

37. Shilpa, E.R., Gayathri, V.: Encapsulation of $\mathrm{Cu}(\mathrm{II})\left[2-\left(2^{\prime}\right.\right.$-hydroxyphenyl)benzimidazole]2 within zeolite nano-cavity: structural properties and its catalytic activity towards phenol and styrene oxidation. J. Environ. Chem. Eng. 4, 4194-4206 (2016). https:// doi.org/10.1016/j.jece.2016.09.022

38. Rouquerol, F., Rouquerol, J., Sing, K.S., Llewellyn, P.L., Maurin, G.: Adsorption by Powders and Porous Solids Principles, Methodology and Applications. Elsevier, Amsterdam (2014)

39. Bortolatto, L.B., Boca Santa, R.A.A., Moreira, J.C., Machado, D.B., Martins, M.A.P.M., Fiori, M.A., Kuhnen, N.C., Riella, H.G.: Synthesis and characterization of Y zeolites from alternative silicon and aluminium sources. Microporous Mesoporous Mater. 248, 214-221 (2017). https://doi.org/10.1016/j.micro meso.2017.04.030

40. Guimarães, J., Fernandes, C., Melo, D., Peres, S., Souza, L.D., Regina, M.: Production of light hydrocarbons from pyrolysis of heavy gas oil and high density polyethylene using pillared clays as catalysts. J. Anal. Appl. Pyrolysis. 126, 70-76 (2017). https:// doi.org/10.1016/j.jaap.2017.06.023

41. Miskolczi, N., Buyong, F., Angyal, A., Williams, P.T., Bartha, L.: Two stages catalytic pyrolysis of refuse derived fuel: production of biofuel via syncrude. Bioresour. Technol. 101, 8881-8890 (2010). https://doi.org/10.1016/j.biortech.2010.06.103

42. De Stefanis, A., Cafarelli, P., Gallese, F., Borsella, E., Nana, A., Perez, G.: Catalytic pyrolysis of polyethylene: a comparison between pillared and restructured clays. J. Anal. Appl. Pyrolysis. 104, 479-484 (2013). https://doi.org/10.1016/j.jaap.2013.05.023

43. Dou, G., Goldfarb, J.L.: In situ upgrading of pyrolysis biofuels by bentonite clay with simultaneous production of heterogeneous adsorbents for water treatment. Fuel 195, 273-283 (2017). https ://doi.org/10.1016/j.fuel.2017.01.052

44. Speight, J.G., Exall, D.I.: Refining Used Lubricating Oils. CRC Press, Boca Raton (2014)

45. Rudnick, L.R. (ed.): Lubricant Additives Chemistry and Applications. CRC Press, Boca Raton (2017)

46. Wan Mahari, W.A., Zainuddin, N.F., Chong, C.T., Lee, C.L., Lam, W.H., Poh, S.C., Lam, S.S.: Conversion of waste shipping oil into diesel-like oil via microwave-assisted pyrolysis. J. Environ. Chem. Eng. 5, 5836-5842 (2017). https://doi.org/10.1016/j. jece.2017.11.005

47. Shiung, S., Keey, R., Kui, C., Chase, H.A.: Catalytic microwave pyrolysis of waste engine oil using metallic pyrolysis char. Appl. Catal B Environ. 176, 601-617 (2015). https://doi.org/10.1016/j. apcatb.2015.04.014

48. Abrevaya, H.: Cracking of naphtha range alkanes and naphthenes over zeolites. In: From Zeolites to Porous MOF Materials, pp. 1244-1251. Elsevier, Amsterdam (2007)

49. Mante, O.D., Agblevor, F.A., Oyama, S.T., McClung, R.: Catalytic pyrolysis with ZSM-5 based additive as co-catalyst to Y-zeolite in two reactor configurations. Fuel 117, 649-659 (2014). https:// doi.org/10.1016/j.fuel.2013.09.034

50. Bridgwater, A.V.: Review of fast pyrolysis of biomass and product upgrading. Biomass Bioenerg. 38, 68-94 (2012). https://doi. org/10.1016/j.biombioe.2011.01.048

51. Zafar, R., Watson, J.S.: Adsorption of tetradecanoic acid on kaolinite minerals: using flash pyrolysis to characterise the catalytic efficiency of clay mineral adsorbed fatty acids. Chem. Geol. 471, 111-118 (2017). https://doi.org/10.1016/j.chemgeo.2017.09.020

52. Speight, J.G.: The Chemistry and Technology of Petroleum. CRC Press, Boca Raton (2014)

53. Ayanoğlu, A., Yumrutaş, R.: Production of gasoline and diesel like fuels from waste tire oil by using catalytic pyrolysis. Energy 103, 456-468 (2016). https://doi.org/10.1016/j.energy.2016.02.155

Publisher's Note Springer Nature remains neutral with regard to jurisdictional claims in published maps and institutional affiliations. 